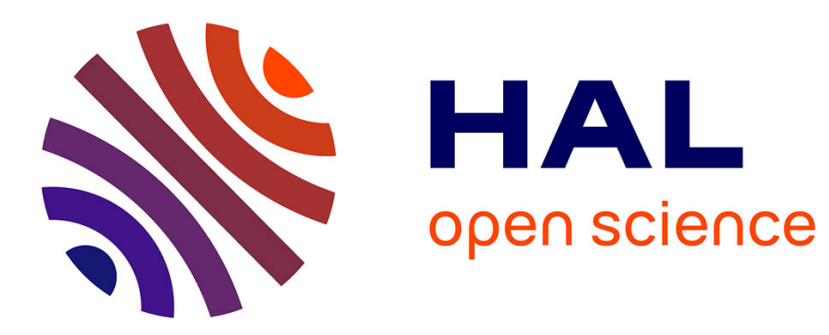

\title{
Influence of Trace Elements on Hot Ductility of an Ultra High Purity Invar Alloy
}

\author{
M. Perrot-Simonetta, A. Kobylanski
}

\section{To cite this version:}

M. Perrot-Simonetta, A. Kobylanski. Influence of Trace Elements on Hot Ductility of an Ultra High Purity Invar Alloy. Journal de Physique IV Proceedings, 1995, 05 (C7), pp.C7-323-C7-334. 10.1051/jp4:1995739 . jpa-00254033

\section{HAL Id: jpa-00254033 https://hal.science/jpa-00254033}

Submitted on 1 Jan 1995

HAL is a multi-disciplinary open access archive for the deposit and dissemination of scientific research documents, whether they are published or not. The documents may come from teaching and research institutions in France or abroad, or from public or private research centers.
L'archive ouverte pluridisciplinaire HAL, est destinée au dépôt et à la diffusion de documents scientifiques de niveau recherche, publiés ou non, émanant des établissements d'enseignement et de recherche français ou étrangers, des laboratoires publics ou privés. 


\title{
Influence of Trace Elements on Hot Ductility of an Ultra High Purity Invar Alloy
}

\author{
M.T. Perrot-Simonetta* and A. Kobylanski \\ Ecole Nationale Supérieure des Mines de Saint-Etienne, 158 cours Fauriel, 42023 Saint-Etienne cedex 2, \\ France \\ * Centre de Recherche CREAS, BP. 140, 57360 Amnéville, France
}

\begin{abstract}
Like steels, austenitic INVAR alloys Fe-Ni $36 \%$ show a large ductility trough between $500^{\circ} \mathrm{C}$ and $1100^{\circ} \mathrm{C}$. To understand hot brittleness mechanisms and especially trace element effects, synthetic alloys were prepared using ultra-high purity iron and nickel doped with selected amounts of carbon, sulphur, boron, aluminium, and nitrogen. Four kinds of synthetic alloys were studied to establish the intrinsic influence of sulphur, the combined effects of sulphur and precipitates such AIN or BN, and the effect of boron in the presence of sulphur, on ductility and fracture mechanisms. We propose several mechanisms to explain the loss and the recovery of ductility for each of the studied alloys, and then define the field of temperatures where these mechanisms control ductility.
\end{abstract}

\section{INTRODUCTION}

During hot forming of steels (continuous casting, hot rolling, forging, etc) cracks often propagate along grain boundaries leading to low ductility and poor mechanical properties. This damage is generally attributed to the presence of trace elements in the metal. Sulphur and also precipitates (carbides, nitrides) are often incriminated in industrial steels. However, chemical composition is not the only parameter that influences ductility. Studies carried out on industrial steels show that ductility can vary with the conditions of strain (deformation rate, stress distribution and temperature), and also with microstructure (grain size, crystallographic structure, location of precipitates) resulting from heat treatments.

Although a great many results have been obtained on industrial steels, the detailed mechanisms controlling ductility are not well established, doubtless because industrial steels are complex and their composition difficult to control, especially for elements present at very low concentration. To fill this gap, the laboratory (St Etienne School of Mines) has been working for the last twelve years on the influence of trace elements on the mechanical properties and ductility of steels.

\subsection{General processes and objectives}

With the aim of understanding the influence of one given element on metal properties, the laboratory has developed very effective techniques for the purification of metals and can produce ultra high purity iron and nickel : $99,991 \%$ and 99,979\% respectively [1]. Moreover, technical means are available to dope these pure metals with selected amounts of carbon, sulphur, boron, aluminium, nitrogen... without involuntary contamination (by oxygen for example). With the synthetic iron alloys produced in recent years, it had been shown that the simultaneous presence of sulphur and intergranular precipitates of AlN in Fe-C can induce serious intergranular embrittlement between $800^{\circ} \mathrm{C}$ and $1050^{\circ} \mathrm{C}$, whereas sulphur alone only has a small effect on the ductility of pure Fe-C at the same concentration $(10-20 \mu \mathrm{g} / \mathrm{g})$, and whereas AlN precipitates alone are not embrittling [2-4].

Because the same observations have been performed with elements such as $\mathrm{Se}$, Te or with $\mathrm{NbCN}, \mathrm{VCN}$, precipitates, the authors [4-5] proposed that ductility loss is the result of the combined effect of segregation and precipitation at grain boundaries in iron. They suppose that this could be of true for many other metals. 
To describe in greater detail the mechanisms involved in the ductility trough phenomenon, observations are needed on the damaged hot microstructure. These observations are very difficult to perform on iron because allotropic transformation occurs and erases the gamma grain boundaries [4, making void nucleation sites difficult to locate with precision [4].

Like steels, industrial INVAR alloys such as FeNi $36 \%$ are crack-sensitive at temperatures near $600^{\circ} \mathrm{C}$ [ 1], while their structure is austenitic at all temperatures [6-7].

For these reasons, an FeNi $36 \%$ alloy was chosen to verify the hypothesis of the combined effect of segregation and precipitates.

\begin{tabular}{|c|c|ccccc|c|c|}
\hline GROUP & Name & C & S & B & N & A & N/x & $\begin{array}{c}\text { Grain } \\
\text { size }\end{array}$ \\
\hline (I) & S4 & 120 & 44 & $/$ & $<10$ & $/$ & & $300-400$ \\
& S7 & 200 & 7 & $/$ & $<10$ & $/$ & & 300 \\
& S10 & 160 & 12 & $/$ & $<10$ & $/$ & & 230 \\
& S35 & 210 & 35 & $/$ & $<10$ & $/$ & & 150 \\
\hline (II) & S7 A1N & 160 & 7 & $/$ & 82 & 220 & 0.4 & 500 \\
S+ Al, N & S10 A1N & 150 & 13 & $/$ & 40 & 320 & 0,13 & $>500$ \\
\hline (III) & S10 B5 N & 210 & 12 & $<$ & 35 & $/$ & 7 & $200-400$ \\
S+ B, N & S10 B20 N & 120 & 10 & $20-30$ & $60-70$ & $/$ & 2,6 & 500 \\
& S5 B30 N & 160 & 5 & 30 & 35 & $/$ & 1,15 & $>500$ \\
& S10 B65 N & 180 & 10 & $65-90$ & $65-70$ & $/$ & 0,8 a 1 & $200-300$ \\
\hline (IV) & S7 B 25 & 230 & 7 & 25 & $<$ & $/$ & $0,0$. & $>500$ \\
S+B & S10 B 20 & 230 & 12 & 20 & $<$ & $/$ & $0,0 .$. & $250-500$ \\
\hline
\end{tabular}

Table 1 : Chemical composition of FeNi $36 \%$ alloys and grain size $(\mu \mathrm{m})$ with $\mathrm{x}=\mathrm{Al}$ or $\mathrm{B}$

\subsection{Experimental procedure}

The trace elements used to dope ultra high purity FeNi $36 \%$ alloy are those suspected of being involved in brittleness i.e. sulphur, aluminium, boron, nitrogen. Carbon is added to limit grain size [4].

Four kinds of synthetic alloys were prepared (see table 1) to establish the intrinsic influence of sulphur additions (group I), the combined effects of sulphur and AIN (group II) or BN precipitates (group III) and the effects of boron in the presence of sulphur (group IV), on the ductility and fracture mechanisms of FeNiC alloy.

After hot forming (at $1200^{\circ} \mathrm{C}$ ) and homogenization at $1200^{\circ} \mathrm{C}$ of the different doped alloys, a heat treatment at $850^{\circ} \mathrm{C}$ for 1 hour (furnace cooling) was performed to obtain both sulphur segregation and AlN or BN precipitation [8] as in iron [2]. After this treatment (known as TT-HPS) the metal is considered to be in the state designated D1.

The distribution of impurities was determined by SEM, TEM and AES when possible [1] [8, in state D1.

Hot tensile tests were performed after 5 min of treatment at a temperatures in the range from $500^{\circ} \mathrm{C}$ to $1150^{\circ} \mathrm{C}$, and at room temperature in an argon atmosphere [1] [4], temperature ; at this stage, the state of the metal is designated D2. The initial strain rate is relatively low $\left(2.10^{-3} 5^{-1}\right)$ and was chosen because it is the one currently used to simulate hot cracking [9-10].

Ductility is measured by the reduction of area after rupture (RA \%).

Microstructural and fractographic observations were performed on the broken samples quenched immediately after the tensile test.

To determine the location of damage and the deformation mechanisms, longitudinal cross sections of quenched samples were systematically examined. 


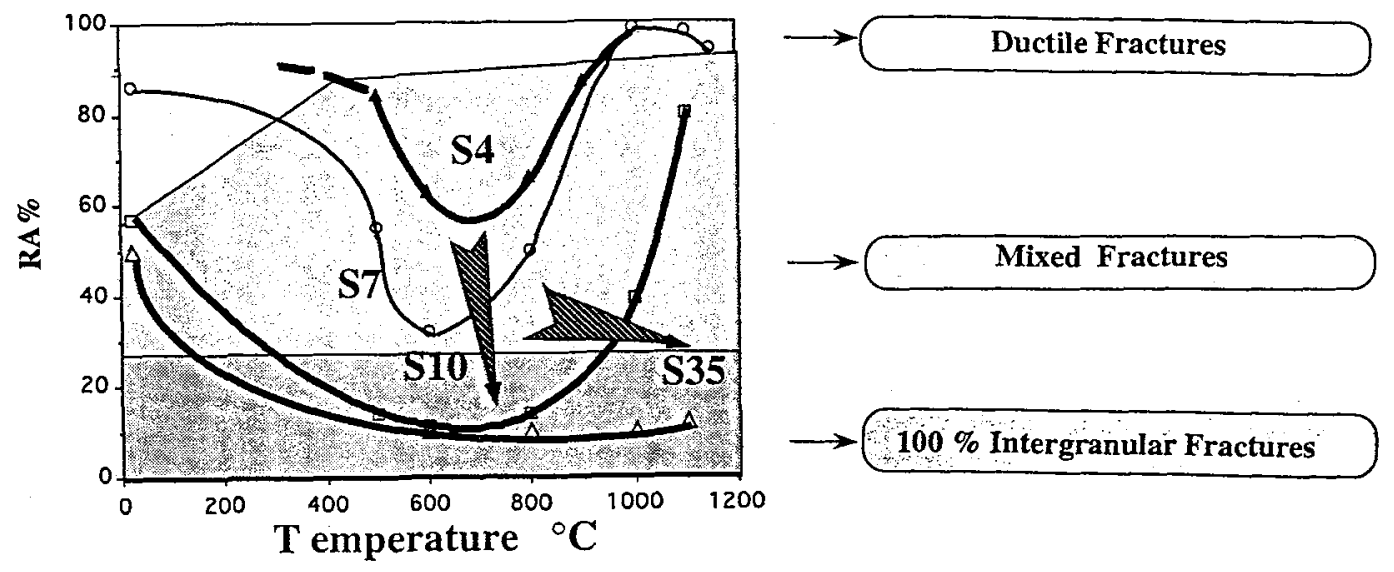

Figure 1 : Reduction of area (RA \%) versus temperature tensile test for group I alloys containing respectively 4, 7, 12 and 35 $\mu \mathrm{g} / \mathrm{g}$ of sulphur

\section{INFLUENCE OF SULPHUR ADDITIONS}

\subsection{Ductility and damage}

\subsubsection{Observations}

As shown in figure 1, the ductility of the Group I alloys is dependent on both sulphur concentration and temperature. A ductility trough is observed for the four alloys, even for the reference alloy containing only $4 \mu \mathrm{g} / \mathrm{g}$ of sulphur [1]. The ductility trough becomes larger and deeper when sulphur concentration increases.

The ductility loss occurs round about $500^{\circ} \mathrm{C}$ for the reference alloy $\mathrm{S} 4$ while the $\$ 35$ alloy is brittle from room temperature. The ductility minimum modes of fracture are characterized by $100 \%$ intergranular fracture surfaces for $\mathrm{S} 10$ and $\mathrm{S35}$, whereas the worst fracturing occurs in a mixed mode (partly intergranular, partly ductile) for S4 and S7. At a very high magnification, the intergranular facets are sprinkled with microvoids, whose aspect depends on sulphur concentration and temperature. As an example, at $600^{\circ} \mathrm{C}$, for a low sulphur content alloy S7, microvoids coalesced leading to a localized ductile intergranular fracture (figure $2 \mathrm{a}$ ) whereas for $\mathrm{S} 35$, microvoids are isolated on flat facets leading to brittle intergranular fracture (figure 2 b) reminiscent of dimple creep intergranular fracture facets [11.

\subsubsection{Cavitation and crack propagation}

For each of the Group I alloys, longitudinal sections of quenched samples show that the preferential cavity nucleation sites at temperatures up to $500^{\circ} \mathrm{C}$ are intergranular triple points. The proportion of triple points sensitive to cracking increases with the sulphur concentration.

Confirmation that fracture occurs by a mechanism of nucleation, growth and coalescence of microvoids at the head of cracks is given by figure 3 . This figure shows that the number of nucleation sites increases with sulphur concentration. Moreover, crack propagation seems to be easier at a high sulphur content (cracks are propagated along one or more grain boundaries in $\mathrm{S} 10$ against a stress and sample deformation which is less than for S4 alloy).

To understand the mechanism of ductility loss and recovery, we have to explain how sulphur can influence the nucleation and growth of damage and what the effect of temperature is.

First of all, because precipitates are preferential sites of damage in metals, we have to verify the presence of sulphides or carbides inside the intergranular microvoids. No precipitates were detected by SEM observations. Although thin foil TEM analysis revealed sulphides or carbides [1], their intragranular location makes it improbable that they are the main origin of brittleness. 


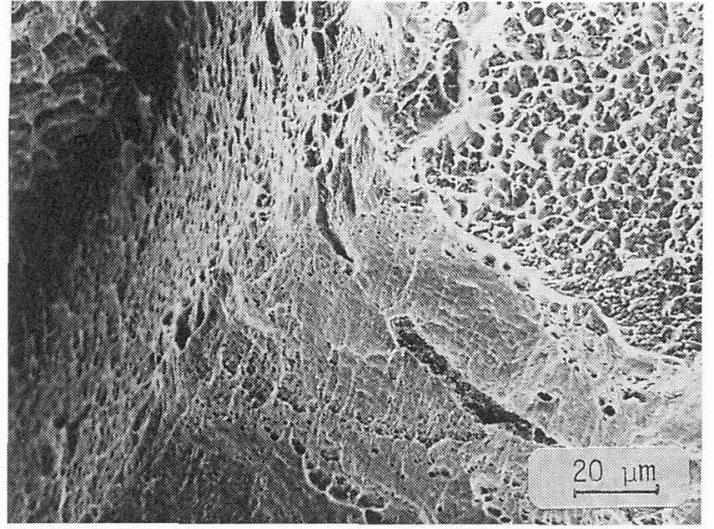

(a)

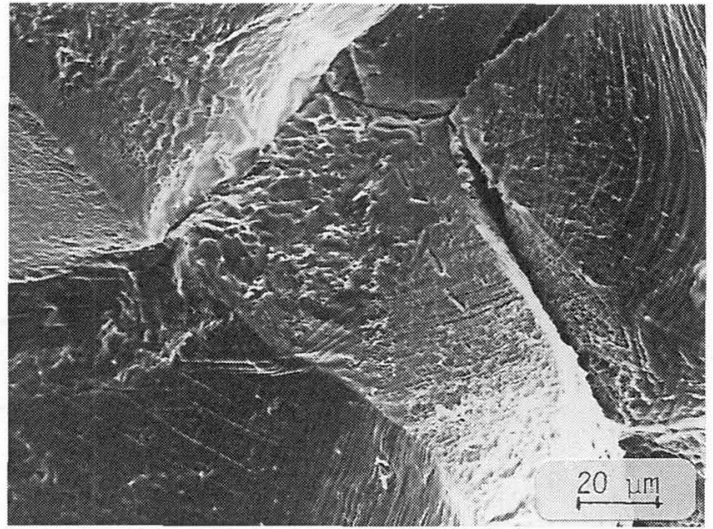

(b)

Figure 2 : (a) Intergranular facet of the mixed fracture surface of $S 7$ broken at $600^{\circ} \mathrm{C}$

(b) Intergranular facet of the $100 \%$ intergranular fracture surface of $\mathrm{S} 35$ broken at $600^{\circ} \mathrm{C}$ [extracted from ref [1]]

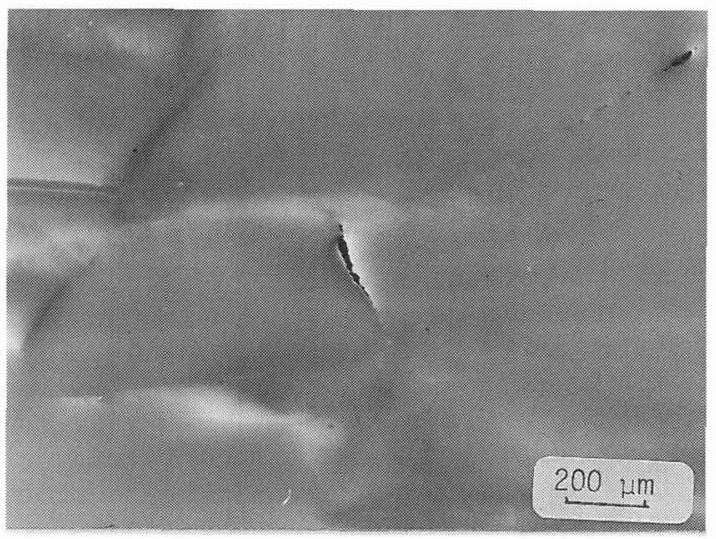

(a)

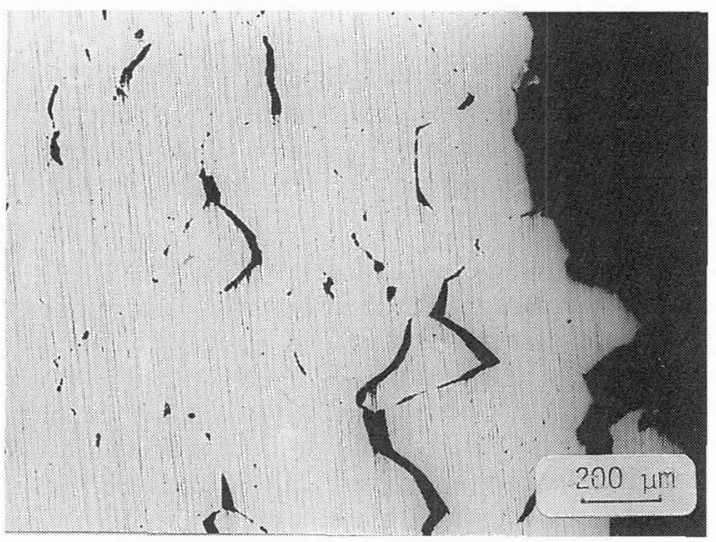

(b)

Figure 3 : (a) Example of cracks initiated at GB triple points with crack propagation controlled by nucleation,growth and coalescence at the head of cracks ( $\mathrm{S} 4$ alloy at $800^{\circ} \mathrm{C}$ )

(b) Damaging distribution of cracks and voids for $\$ 10$ alloy at the same temperature $\left(800^{\circ} \mathrm{C}\right)$ for $100 \%$ intergranular fracture

On the other hand, TEM shows faceted grain boundaries, a phenomenon which has been attributed to sulphur segregation in Ni-S alloys [12]. Because the high-sulphur alloy S35 is brittle at room temperature, the hypothesis of sulphur segregation as a microvoid nucleating factor seems very probable but needs to be verified, first of all for low sulphur alloys.

If sulphur is segregated to grain boundaries, it will weaken them, so crack propagation will be easier.

\subsection{Sulphur segregation at grain boundaries}

To identify the segregated elements at grain boundaries, and evaluate the influence of their bulk concentration and of temperature on intergranular segregation level we used a new quantitative method [ 13].

Tensile tests were performed in the AES apparatus, at room temperature and at a low strain rate $1,310^{-4}$ $\mathrm{s}^{-1}$. S10 and S35 alloys were broken after the TT-HPS heat treatment, to evaluate the initial level of 
segregation (State D1). All the grain boundaries analysed show very high sulphur concentration levels, $\mathrm{Cj}(\mathrm{s}) \approx 0,48$ for $\mathrm{S} 10$ and 0,58 for $\mathrm{S} 35$. On the other hand, no trace of carbon was detected [1].

Because the TT-HPS heat treatment ends with a slow continuous furnace cooling, sulphur probably segregates during cooling from $850^{\circ} \mathrm{C}$ to room temperature, leading to a grain boundary enrichment factor higher than that of equilibration at $850^{\circ} \mathrm{C}$.

To compare State D1 with the sulphur segregation equilibrium state, we studied the evolution of sulphur segregation with temperature and sulphur content. Equilibrium heat treatment at $625^{\circ} \mathrm{C}$ was performed on FeNiCS alloys containing 7,12 and $20 \mu \mathrm{g} / \mathrm{g}$ of sulphur.

To facilitate intergranular fracture, $\mathrm{BN}$ precipitates were introduced into these alloys before heat treatment $\left[1^{\circ}\right.$.

From the measured sulphur concentration at grain boundaries at $625^{\circ} \mathrm{C}$, we evaluated the segregation energy equal to $(-92) \mathrm{kJ} / \mathrm{mol}$, supposing that sulphur segregation follows a Maclean law [14] :

$$
\theta j(s)=\frac{\operatorname{Cvol}(s) \exp \left(-\Delta G^{s j} / R T\right)}{1+\operatorname{Cvol}(s) \exp \left(-\Delta G^{s j} / R T\right)}
$$

where :

Cvol(s) is the bulk concentration of sulphur (or atomic fraction of sulphur)

$\theta j(s)=\frac{C j}{\text { equil(s) }}$ is the mean ratio of occupation of intergranular sites at the temperature considered $\mathrm{Ci} \max (\mathrm{s})$

$\Delta \mathrm{G}^{\mathrm{sj}}$ is the sulphur segregation free energy.

This result is coherent with the Ni-S system, studied by Larere 115. Comparing the Maclean segregation isotherms, with the measured segregation in State D1, we estimated that grain boundary enrichment corresponding to state D1 is similar to the equilibrium segregation at about $600-625^{\circ} \mathrm{C}$ for $\mathrm{S} 10(\theta \mathrm{j} \approx 0,8, \mathrm{Cj}(\mathrm{s}) \approx 48 \%)$, and at less than $500^{\circ} \mathrm{C}$ for $\mathrm{S} 35(\theta \mathrm{j} \approx 1, \mathrm{G}(\mathrm{s})=58 \%)$.

This result is coherent with the diffusion theory : under a given temperature depending on the bulk concentration level of sulphur, diffusion is too slow to allow dissolved sulphur to attain grain boundaries and increase segregation. Then we suppose that segregation concentration could be equivalent to that at around $650^{\circ} \mathrm{C}$ for $\mathrm{S} 7(\theta j=0,65, \mathrm{Cj}(\mathrm{s})=34 \%)$ and around $700^{\circ} \mathrm{C}$ for $\mathrm{S} 4(\theta \mathrm{j} \approx 0,4, \mathrm{Cj}(\mathrm{s})=23 \%)$ after furnace cooling at $400^{\circ} \mathrm{C} / \mathrm{h}($ State $\mathrm{D} 1)$.

\subsection{Temperature effects}

Hot tensile tests were performed, after a 5 minute period at test temperature. During this stage, State D1 can evolve to approach equilibrium segregation at the temperature given. The D2 State obtained depends on the test temperature, and also on the kinetics of dissolution of any sulphides that may have been formed in the matrix during furnace cooling. Because of that, to evaluate the sulphur concentration at grain boundaries just before tensile test (State D2), we have to know the law governing the solubility of sulphur in FeNi 36\% alloy.

As a matter of fact, at temperatures where sulphides are present in the alloys $(\mathrm{T}<\mathrm{Tsol}(\mathrm{s}))$, the Maclean equation has to be corrected and becomes:

$$
\theta \mathrm{j}(\mathrm{s})=\frac{\mathrm{A} \exp \left(\left(-\Delta \mathrm{G} \operatorname{seg}-\Delta \mathrm{H}_{\mathrm{sol}} / \mathrm{RT}\right)\right.}{1+\mathrm{A} \exp \left(\left(-\Delta \mathrm{Gse}-\Delta \mathrm{H}_{\mathrm{sol}}\right) / \mathrm{RT}\right)}
$$

The observations of fracture surfaces, combined with the P. Marcus studies [17], enable us to express the solubility limit law of sulphur in FeNi $36 \%$ alloy by the following equation :

where Csol(s) is the atomic fraction of sulphur.

$$
C_{\text {sol }}(s)=0,00606 \cdot \exp \frac{(-48500)}{R T}
$$




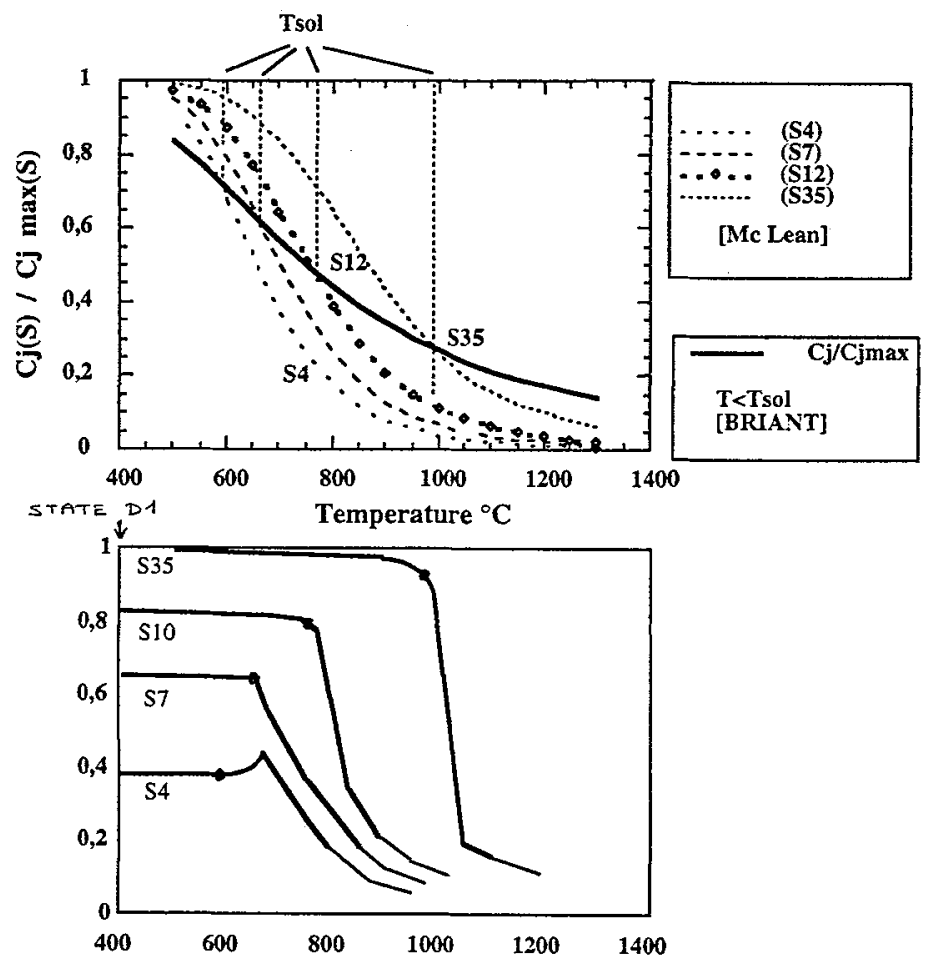

Figure 4 : (a): Evolution of $6 \mathrm{j}(\mathrm{s})$ with temperature at equilibrium* if $\mathrm{T}<\mathrm{T}$ sol Briant law is available (see text)

* if $\mathrm{T}>\mathrm{Tsol}$ Maclean low is available (see text)

(b): Assumptions for the value of $\theta \mathrm{j}(\mathrm{s})$ at stage $\mathrm{D} 2$ after $5 \mathrm{~min}$ reheating from State $\mathrm{D} 1\left(20^{\circ} \mathrm{C}\right)$

Tsol is indicated by the black point

Figure $4 \mathrm{a}$ represents the evolution of $\theta \mathrm{j}(\mathrm{s})$ with temperature at equilibrium, considering the Maclean equation (dotted lines) and the Briant equation (full lines). With the kinetic considerations, it is highly probable that equilibrium is not reached for the D2 State corresponding to the low temperature test (under Tsol).

As a matter of fact, sulphides formed during cooling cannot be dissolved during the 5 min of temperature stabilization. Under Tsol, for each of the alloys, we suppose that segregation will stay at the same level as state D1. On the other hand, at high temperatures, when sulphides are totally dissolved, $(T>$ Tsol), we suppose that sulphur can desegregate rapidly. In respect of these assumptions, we propose an evaluation of the ratio $\theta j(s)$ with the temperature for each alloy of group I after 5 minutes of reheating at tensile test temperature (State D2). This evolution is presented in figure $4 \mathrm{~b}$.

\section{HOT BRITTLENESS MECHANISM}

\subsection{Can segregation alone explain the ductility trough?}

Because there is evidence of sulphur segregation in the alloys just before the tensile test (State D2), we will try to explain the ductility trough only by sulphur segregation considerations.

At room temperature, comparison of figure $4 \mathrm{~b}$ and figure 1 allows us to state that if $\theta j(s)$ is above 0,65 , then grain boundary decohesion can be observed.

When the temperature approaches $500^{\circ} \mathrm{C}$, the sulphur segregation ratio is constant for all of the Group 1 alloys. However, ductility is lower at $600^{\circ} \mathrm{C}$ than at room temperature for each alloy. It is then impossible to find a correlation between segregation level at State D2 and the ductility resulting from this state. 
When temperature increases, segregation occurs less and less : for example, for $S 10$ at $1000^{\circ} \mathrm{C}, \theta=0,1$ ). If sulphur segregation is the only phenomenon causing embrittlement, then we should observe very good ductility when $\theta=0,1$. However the observations are not coherent with this hypothesis (S10 shows considerable embrittlement at $1000^{\circ} \mathrm{C}$ ) ; this indicates that other mechanisms contribute to ductility loss around $500^{\circ} \mathrm{C}$

On the basis of the observations of triple point boundary damage, we may suppose that grain boundary sliding is one of the phenomena that could explain the differences of ductility observed between $20^{\circ} \mathrm{C}$ and $500-600^{\circ} \mathrm{C}$. This mechanism was observed at the sample surface at $600^{\circ} \mathrm{C}$ in several instances [1].

In conclusion we can say that the ductility trough is the result of several mechanisms : the first kind increase damage (Ai) the second kind lead to better ductility (Bi). Figure 5 is a diagram of the ductility trough.

When several Ai mechanisms are present together, their effect is additive and leads to a deep ductility trough. The temperature of the ductility trough start Ta is defined by one of the Ai mechanisms. When a Bi mechanism appears (Tb), ductility generally starts to recover.

One of the mechanisms will be called A1 : segregated sulphurs at grain boundaries induce decohesion. We can say that another mechanism inducing cavitation (termed A3) could be the mechanism of grain boundary sliding inducing cavitation described by several authors for intergranular creep rupture [11], [18-20].

A1 and A3 interact as shown by Afshar [21]. To these mechanisms we can add two others [22-24]. These mechanisms can be either superficial segregation of sulphur at the cavity free surface (A4') or dynamic segregation of sulphur at stress concentration sites (A4") [1].

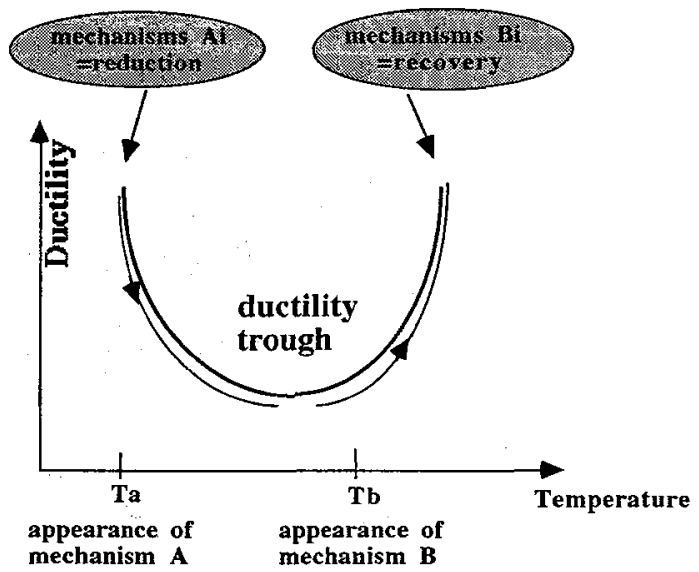

Figure 5 : The ductility trough results from the competition between several thermally activated $\mathrm{Ai}$ and $\mathrm{Bi}$ mechanisms

\subsection{Sulphur segregated at free surfaces and ductility}

Following the Hirth theory [24], superficial segregation of elements influences rupture energy expressed by :

$$
\gamma=\gamma^{\circ}+\Gamma j\left[\Delta \mathrm{Gsurf}-\Delta \mathrm{G}_{\mathrm{GB}}-\mathrm{RT} \operatorname{Ln} 2\right]
$$

where $\}=2 \gamma$ surf $-\gamma_{\mathrm{GB}} \cdot[14]$ is the ideal rupture energy of a grain boundary without impurity $(\mathrm{J} / \mathrm{m} 2)$ and where $\Gamma j$ is the excess quantity of segregated atoms (moles of segregated atoms per square meter). 
We measured equilibrium segregation of sulphur on a free surface between 600 and $1100^{\circ} \mathrm{C}$ for the $\mathrm{S} 35$ alloy and estimate $\Delta$ Gsurf to be equal to $-124 \mathrm{~kJ} / \mathrm{mol}$.

Because $\Delta \mathrm{G}$ surf is less than $\Delta \mathrm{G}_{\mathrm{GB}}(-92 \mathrm{~kJ} / \mathrm{mol})$ then $\left(\Delta \mathrm{G}\right.$ surf $\left.\left.-\Delta \mathrm{G}_{\mathrm{GB}}\right)<0\right)$, we can admit that sulphur is a strong fracture energy reducer.

This theory gives us a partial explanation of why ductility is dependent on sulphur segregation at GB's and free surfaces.

\section{DUCTILITY RECOVERY}

Ductility starts to recover at a temperature depending on sulphur level. For low sulphur alloys ductility starts to increase at temperatures over $800^{\circ} \mathrm{C}$, when $\mathrm{S}$ starts to desegregate, figure 4 .

We may suppose, then, that sulphur desegregation could be a necessary condition to enable ductility to be recovered.

For the low sulphur alloy $S 4$ we estimated that at $800^{\circ} \mathrm{C}$ the level $\theta \mathrm{s} \approx 0,2$. The same level $\theta \mathrm{s}$ is obtained for a high sulphur level $\mathrm{S} 35$ at a temperature equal to $1100^{\circ} \mathrm{C}$.

However $\mathrm{S} 35$ alloy at $1100^{\circ} \mathrm{C}$ stay less ductile then $\mathrm{S} 4$ at $800^{\circ} \mathrm{C}$. This comparison shows us that sulphur desegregation (termed the B1 mechanism) is necessary but not sufficient to explain ductility recovery.

In fact, to reduce cavitation, its also necessary to reduce GB sliding (reduce the influence of A3) and also to reduce surface segregation (which also reduces A3). As shown in [1] ductility recovery is generally observed consecutively with ripples on intergranular facets.

The origin of the ripples seems to be either grain boundary migration leading to serrated grain boundaries or the new grains resulting from dynamic recovery processes (recrystallization or restoration) following microstructural observations (figure 6).

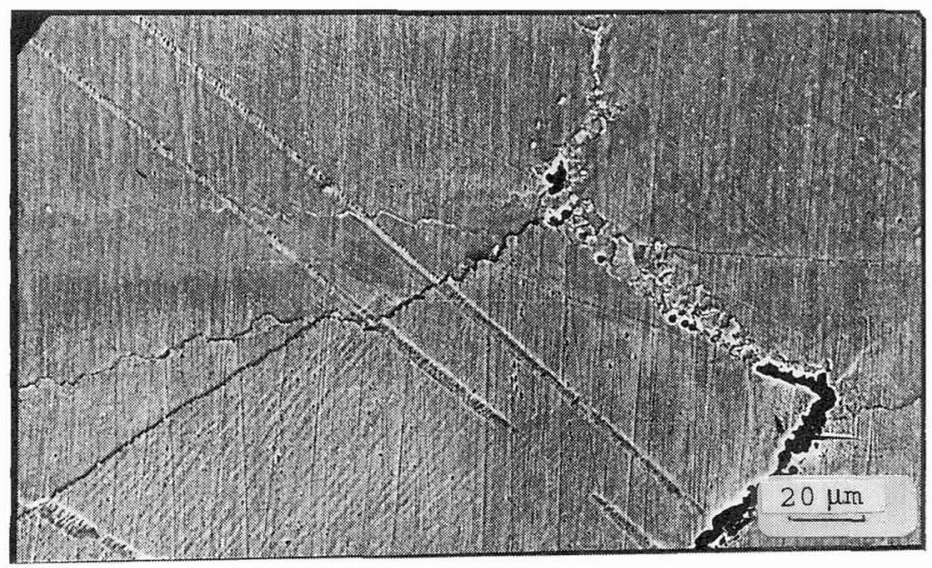

Figure 6 : Serrated grain boundaries and dynamic recrystallization at $800^{\circ} \mathrm{C}$ for $\mathrm{S} 7$ alloys, linked with an increase of ductility

Then the Bi mechanisms observed in our case and which can act as ductility enhancers are B3 (GB serration), B4 (RDX), B5 (GB migration)). However these 3 mechanisms, to be efficient, have to occur very rapidly, i.e. for low deformation levels. If not, cavities can grow and fracture occurs prematurely .

Finally, we can say that the B3 and B5 mechanisms enhance ductility because they reduce GB sliding ; mechanisms B4 and B5 can isolate cavities into a non-damaged matrix but cannot reduce A4. 


\section{SYNERGETIC EFFECT OF PRECIPITATION AND SEGREGATION}

\subsection{Aluminium nitrides and sulphur (Group II)}

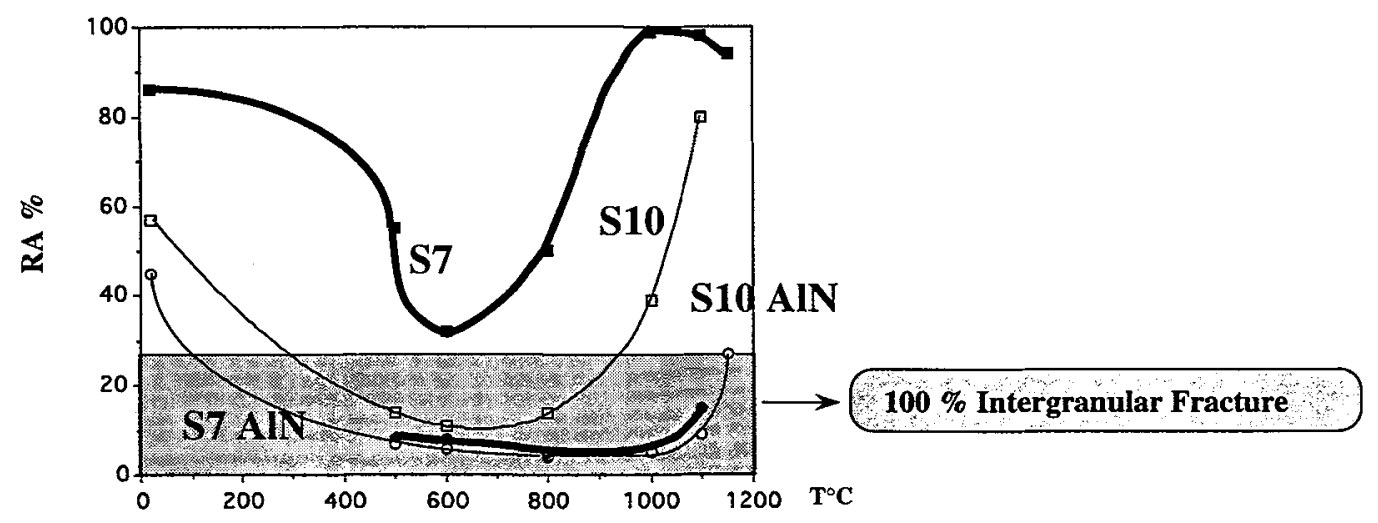

Figure 7 : Ductility curves for the Group II alloys containing sulphur and aluminium nitrides compared with $S 7$ and $S 10$. Fracture surfaces are $100 \%$ intergranular at all temperatures between $500^{\circ} \mathrm{C}$ and $1150^{\circ} \mathrm{C}$

Figure 7 shows ductility curves for Group II with sulphur and aluminium nitrides. The ductility trough becomes deeper and wider with total intergranular fracture.

Nucleation sites of cavitation are on one hand the same as for the Group I alloys (triple points and head of cracks), and on the other hand the interface between intergranular precipitates (cubic AlN) and the ductile matrix.

The addition of the two kinds of nucleation sites leads to an accelerated fracture in the presence of grain boundary sliding and segregated sulphur (figure 8).

All these results show that the synergetic effect of AIN precipitates and segregated sulphur proposed for iron is also valid for the INVAR alloys.

\subsection{Boron nitrides and sulphur (Group III)}

The same phenomenon is observed for INVAR alloys with boron nitride precipitates (figure 9a), resulting from a N/B ratio above 1.15 (see Table 1). MET observations reveal that the BN precipitates are nanometrics and mostly intergranular. The mechanism proposed for Group II alloys, then, seems to be general in the presence of fine intergranular precipitates and sulphur.

\subsection{Complement to the embrittling mechanisms}

We can thus complete the mechanisms named $\mathrm{Ai}$ by the addition of the following one (that we will call A2).

The presence of fine AIN or BN at grain boundaries enhances the number of cavitation sites.

In the presence only of the two mechanisms $A 1$ and $A 2$, at room temperature for example, we can observe a partly intergranular fracture even for a level of segregation $\theta j(\mathrm{~s})$ less than 0,65 (See section 3).

In the presence of grain boundary sliding (A3) with $\mathrm{A} 2$ and $\mathrm{A} 1$, crack propagation is accelerated even for relatively low segregation levels at $1000^{\circ} \mathrm{C}$. 


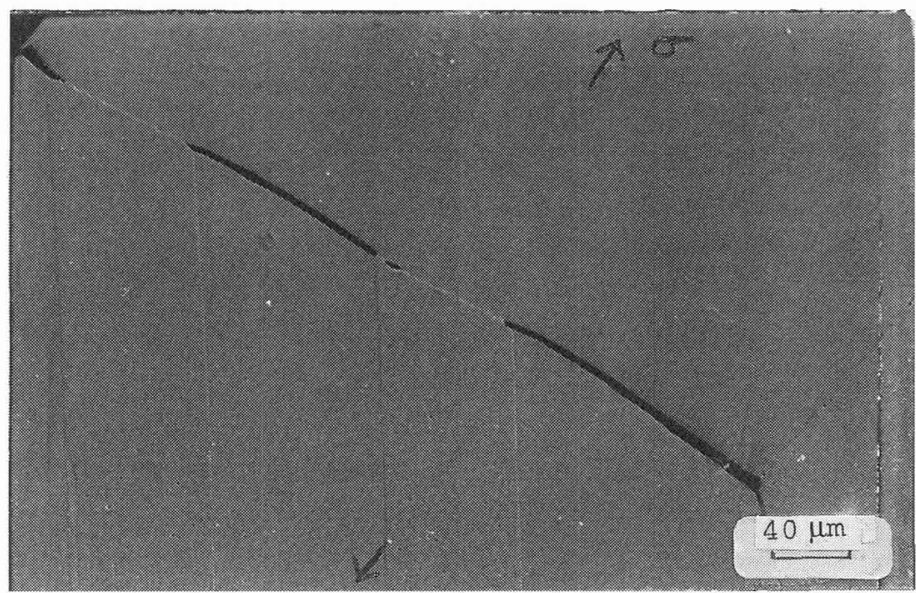

Figure 8 : Intergranular embrittlement of $\mathrm{S} 10 \mathrm{AlN}$ alloy at $800^{\circ} \mathrm{C}$. The crack shown is perpendicular to the tensile test direction (the direction of strain is indicated by the arrows)

\subsection{Complement to ductilizing mechanisms}

The dissolution diagram of $\mathrm{BN}$ in an iron matrix [1] shows us that we recover ductility when $\mathrm{BN}$ is dissolved ; for example at $1150^{\circ} \mathrm{C}$ for the S10B5N alloy (Group III).

We can then complete the Bi mechanism by the $\mathrm{B} 2$ mechanism: the dissolution of precipitates reduces the number of cavitation sites and can lead to better ductility if sulphur at grain boundaries is low enough (B1).
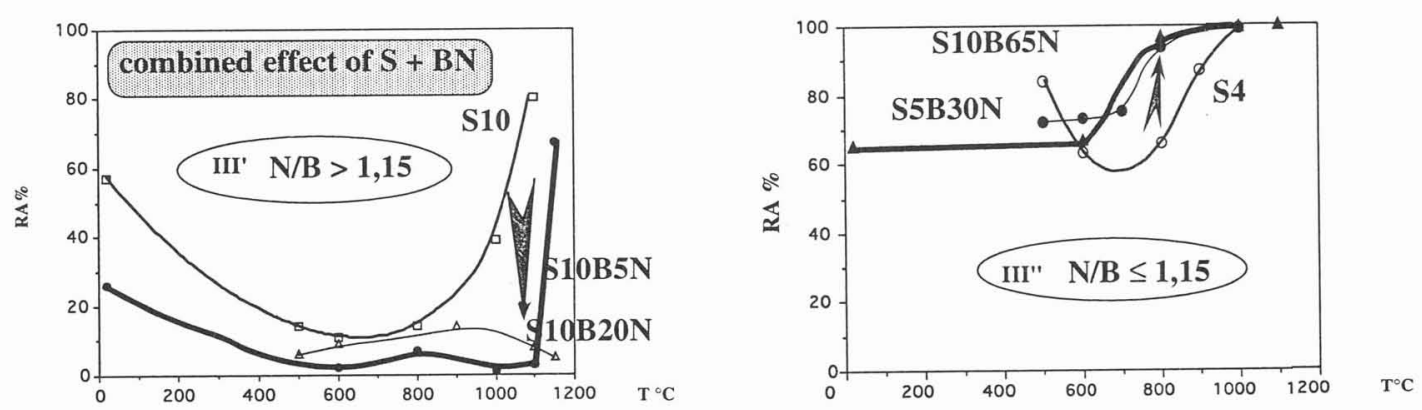

Figure 9 : Ductility curves obtained for the Group III alloys containing sulphur, boron and nitrogen compared with S10 and S4 alloys (a) with a N/B ratio above 1,15 embrittlement is enhanced

(b) with a N/B ratio under 1,15 , ductility is recovered at temperatures up to $800^{\circ} \mathrm{C}$ 


\section{EFFECT OF BORON}

As can be seen in figure $9 \mathrm{~b}$, when the N/B ratio is less than 1,15 than we have totally opposite behaviour of the alloy : ductility is recovered at all temperatures above $800^{\circ} \mathrm{C}$. We have related this phenomenon to free boron.

With the thermodynamic data of BN in iron [26-27], we estimated that THE free boron level is about zero when the N/B ratioS are respectively above 1,15 and equal to $4 \mathrm{ug} / \mathrm{g}$ for the S5B30N alloy and to 15 $\mathrm{ug} / \mathrm{g}$ for the S10B65N alloy (Table 1 and [1]).

To determine whether free boron is really at the origin of the good ductility observed above, we prepared alloys with only sulphur and boron (Group IV).

Figure 10 shows that the behaviour of $\mathrm{S} 7 \mathrm{~B} 25$ and $\mathrm{S} 10 \mathrm{~B} 20$ (Table 1) is equivalent to the previous alloys with N/B ratios under 1,15 and even better than alloy $S 4$.

MET observations were performed to detect the precipitates in these alloys. No boron precipitates were detected. We conclude, then, that boron enhances the ductility of iron-nickel alloys (with $\mathrm{C}$ and $\mathrm{S}$ ) on the condition that the boron is free.

We propose the following assumptions to explain the boron effect :

- free boron segregated at grain boundaries or other interfaces could have an action of repulsion of segregated sulphur (A1), leading to a reduction of $\theta(\mathrm{s})(\mathrm{B} 1)$; then the $\mathrm{A} 1$ mechanism is reduced and perhaps also the $\mathrm{A} 4$ mechanism (free surface segregation)

- free boron segregated at grain boundaries enhances metallic bindings and then reduces cavity nucleation and cavity growth rates during grain boundary sliding (A3)

- free boron could influence dynamic recrystallization or GB migration by its influence on grain boundary energy.

We can then propose some complements to the ductilizing mechanisms by including the mechanism termed BB : boron could modify the mechanisms B1, B4 and B5.

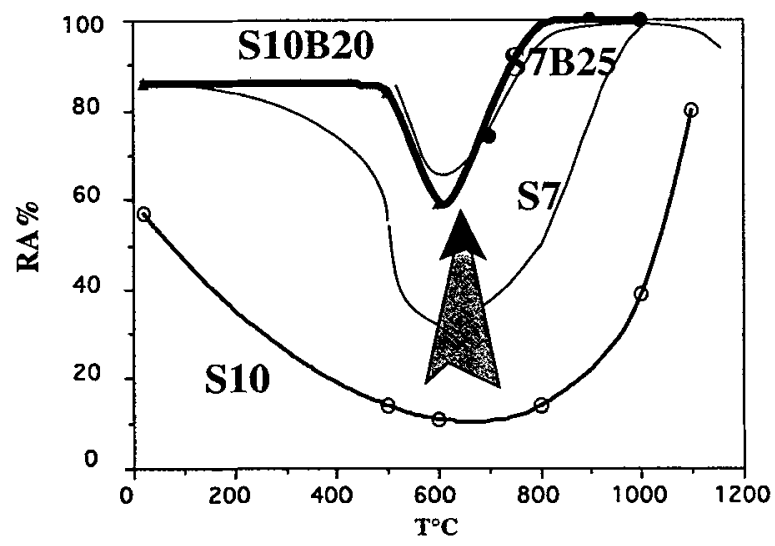

Figure 10 : Ductility curves obtained for the Group IV alloys containing only sulphur and boron The ductility trough is reduced with a total recovery at $800^{\circ} \mathrm{C}$

\section{CONCLUSION}

INVAR alloys are more sensitive to sulphur than iron is : $4 \mu \mathrm{g} / \mathrm{g}$ of sulphur are enough to lower ductility. This can be correlated with the sulphur segregation at grain boundaries, which is very similar to that of nickel.

The combined effect of sulphur and precipitates is valid for iron-nickel alloys and seems to be a general mechanism of embrittlement. 
In this paper, we have shown that several mechanisms are necessary to explain the ductility trough and intergranular embrittlement. The ductility trough results from the competition between these mechanisms, which are more or less dominant, depending on temperature. The competing mechanisms can be separated into two groups : the embrittling mechanisms, such as sulphur segregation (A1), precipitation (A2), grain boundary sliding (A3) and superficial segregation of sulphur and/or dynamic sulphur segregation (A4), and the ductilizing mechanisms, such as sulphur desegregation (B1), precipitation dissolution (B2), serrated grain boundaries (B3), dynamic recrystallization (B4) GB migration (B5) and boron effects (B6).

To increase ductility by adjusting composition, the best solution seems to be to allow free boron to be present : another one could be to translate the temperatures $\mathrm{Ta}, \mathrm{Tb}$ and $\mathrm{Tsol}$.

\section{Acknowledgements}

The authors are grateful to J. P. Colin (IMPHY S.A.), J. M. Castagné (IMPHY.SA) and M. GUTTMANN (IRSID) for useful discussions.

\section{References}

[1] Perrot-Simonetta M. T., Doctorate Thesis (St Etienne School of Mines, 1994)

[2] Heritier P., Fourdeux A., Kobylanski A., Scr metall. 15 (1981) 753-755

[3] Osinkolu G., Doctorate Thesis (St Etienne School of Mines, 1986)

[4] Tacikowski M., Doctorate Thesis (St Etienne School of Mines, 1986)

[5] Yi P., Doctorate Thesis (St Etienne School of Mines, 1989)

[6] Hansen M., Anderko, K. Constitution of binary alloys (Mc Graw - Hill Book Company inc, 1958)

[7] Albertsen J. F., Knuden J. M, Roy-Pousen N.O., Vistisen L., Phys. Scripta 22 (1980) 171-185

[8] Perrot-Simonetta M. T., Kobylanski A., Mem. Sci. Revue Franc. de Métall (1990)689-699

[9] Tacikowski M., Osinkolu G.A., Kobylanski A., Acta Met 36 (1988)995-1004

[10] Suzuki H.G., Nishimura S., Imamura J., Nakamura Y., Trans. ISIJ 24 (1984)169-177

[11] Watanabe T., Met. Trans 14A (1983)531-545

[12] Loier C., Doctorate Thesis (University Paris VI, 1979)

[13] Perrot-Simonetta M.T., Lorenzon C., Biscondi M., Surf. and Interf. Anal 21 (1994) 316-320

[14] Maclean D., Grain boundaries in metals (Oxford University Clarendon Press, 1957)

[15] Larere A., Doctorate Thesis (University Paris XI, 1983)

[16] Briant C.L., Acta Metall. 33 (1985) 1241-1246

[17] Marcus P., Olefjord I., Corrosion 42 (1986) 91-99

[18] Arnaud J.C., Doctorate Thesis (Paris School of Mines, 1987)

[19] Ashby M.F., Gandhi C., Taplin D.M.R, Acta métall 27, Overview nº 3 (1979)699-729

[20] Afshar S., Doctorate Thesis (St Etienne School ofeMines, 1987)

[20] Adda Y., Dupouy J.M., Philibert J., Quere Y., Elements de métallurgie physique (CNRS editions, 1979)Tome 5

[21] Afshar S., Doctorate Thesis (St Etienne School of Mines, 1987)

[22] Hippsley C.A., Acta metall 35 (1987) 2399-2416

[23] Mac Mahon C., Metallkde Z., Bd 75H7 (1984)496-508

[24] Hirth J. P., Rice J.R., Metall.Trans. 11A(1980) 1501-1515

[25] Zhang Y., Zhu F., Xiao J., Scripta Met 25 (1991) 1617-1622

[26] Schanne G., Bulletin CEM 19 (1990) 10/1-10/16

[27] Fountain R.W., Chipman J., Trans. Aime 224 (1962) 533-540 